\title{
ANÁLISE DA ABORDAGEM ERGONÔMICA NAS METODOLOGIAS DE PROJETO DE PRODUTO DE ENGENHARIA
}

\section{ANALYSIS OF THE ERGONOMIC APPROACH IN THE ENGINEERING DESIGN METHODOLOGIES}

\author{
Fabíola Reinert ${ }^{1}$, M. Eng. \\ Leila Amaral Gontijo², D. Sc. \\ (1) Universidade Federal de Santa Catarina \\ e-mail:fabiola.reinert@gmail.com \\ (2) Universidade Federal de Santa Catarina \\ e-mail: leila.gontijo@ufsc.br
}

Palavras-chave: ergonomia, projeto de produtos, metodologia de projeto.

Este artigo faz uma análise de metodologias e modelos de referência para o desenvolvimento de produtos comumente utilizadas na engenharia, para verificar se a ergonomia é abordada e como é abordada pelos autores. Os resultados mostram que a ergonomia é apresentada de forma limitada, não permitindo o adequado entendimento de sua utilização no projeto de produtos.

Key-words: ergonomics, product design, design methodology.

This article analyzes the methodologies and reference models for the product development commonly used in engineering, to verify if the ergonomics approached and how it is approached by the authors. The results show that ergonomics is presented in a limited way, not allowing an adequate understanding of its use in product design.

\section{Introdução}

Em 1987, Wisner conceituou a ergonomia como sendo o conjunto de conhecimentos científicos relacionados ao homem, necessários à concepção de instrumentos, máquinas e dispositivos que possam ser utilizados com o máximo de conforto, segurança e eficiência na atividade realizada (WISNER, 1987).
Atualmente, a definição oficial, determinada pela International Ergonomics Association - IEA em agosto de 2000, declara que a ergonomia é a disciplina científica que trata das interações entre os seres humanos e outros elementos ou sistemas, além da aplicação dados e métodos a projetos a fim de otimizar o bem estar humano e o desempenho global do sistema (IEA, 2015). 


\section{$16^{\circ}$ \\ ERGODESIGN USIHC CINAHPA}

É então considerada uma disciplina orientada aos aspectos da vida humana, reforçada pela compreensão dos limites e características físicas e cognitivas, inseridas nos diversos contextos sociais (MORAES; MONT'ALVÃO, 1998; GOMES FILHO, 2003; IIDA, 2005; FALZON, 2007; ABRAHÃO et al., 2010).

Com relação ao processo de desenvolvimento de produtos, a interação com ergonomistas teve início na década de 80 , quando começaram a participar dos projetos de introdução de novas tecnologias, tendo como base a descrição do trabalho e a busca de um prognóstico do trabalho futuro (JACKSON, 2000).

Neste momento, surgiu a perspectiva de complementaridade entre ergonomia e engenharia, uma vez que desde as primeiras proposições metodológicas surgiu a necessidade de intervir no projeto, sua estrutura e atores (DANIELLOU, 2002; PINSKI, 1992 apud JACKSON, 2000; DUARTE, 2002), já que a ergonomia estuda o ser humano e a engenharia desenvolve equipamentos para o benefício do ser humano (ISMAILA; SAMUEL, 2014). A aplicação da ergonomia no projeto de produtos, portanto, busca ajustar os produtos aos seus usuários potenciais. Neste caso, o foco da ergonomia deve ser nas definições de requisitos e limitações técnicas desde as primeiras fases do projeto (JACKSON; DISCHINGER; DUARTE, 2007).

Sendo assim, a utilização da ergonomia no processo de desenvolvimento de produto é importante para conduzir soluções com mais segurança, fácil manuseio e execução da tarefa, prevenção de doenças ocupacionais e agregação de valores ao produto (SILVA; NETO; FILHO, 1998; DEJEAN; NÄEL, 2007). Além disso, segundo Ciaccia (2013), o sucesso de um produto está intimamente ligado à satisfação do cliente, ou seja, "saciar suas necessidades implícitas e explícitas" (CIACCIA, 2013, p.35).

Dessa forma, a ergonomia se apresenta de forma privilegiada para o projeto de produtos, se convertendo em uma ferramenta básica que possibilita o domínio das bases teóricas e práticas $16^{\circ}$ Ergodesign - Congresso Internacional de Ergonomia e Usabilidade de Interfaces Humano Tecnológica: Produto, Informações Ambientes Construídos e Transporte

$16^{\circ}$ USIHC - Congresso Internacional de Ergonomia e Usabilidade de Interfaces Humano Computador

CINAHPA | 2017 - Congresso Internacional de Ambientes Hipermídia para Aprendizagem. responsáveis pelo entendimento das qualidades e características dos usuários, com a finalidade de poder satisfazer suas necessidades (FLORES et al., 2007).

No entanto, diversos estudos mostram que a integração de aspectos de ergonomia no processo de desenvolvimento de produtos não é algo generalizado (BROBERG, 1997). Considerando que o desenvolvimento de produtos se baseia na resolução de um problema que procura atender uma determinada necessidade humana, é essencial que a preocupação com o usuário final seja considerada desde a concepção do produto até a entrega do mesmo para o mercado. Nesse contexto, a incorporação da ergonomia no projeto vem gradualmente assumindo um papel fundamental na consolidação do produto no mercado (SILVA; NETO; FILHO, 1998).

Para Page et al. (2001), o desenvolvimento de produtos destinados ao uso do ser humano é um processo complexo em que se devem combinar os conhecimentos de diferentes campos da engenharia, biomecânica e os fatores humanos para alcançar um produto que satisfaça as expectativas do consumidor e com ele as da empresa. Sendo assim, para desenvolver adequadamente um produto, é necessário saber o que fazer, para quem fazer, quando fazer e como fazer. A esta organização se dá o nome de metodologia de projeto, ou metodologia de desenvolvimento de produtos (BACK et al., 2008).

De acordo com Back et al. (2008), até o século XVII os produtos eram desenvolvidos por artesãos e foi na revolução industrial que houve a divisão do processo de produção nas atividades de projeto, fabricação e vendas. Após a Segunda Guerra Mundial iniciaram-se estudos sobre a atividade de projeto como uma disciplina independente e desde 1960 encontram-se obras de autores que lidam com a atividade de desenvolvimento de produtos de uma forma mais sistemática: Asimov (1962), Cain (1969), Krick (1965), Vidosic (1969) e Woodson (1966). Na década de 80, Estados Unidos e Inglaterra realizaram estudos para identificar razões para a perda de competitividade de seus produtos, ficando evidente que essas perdas eram 


\section{$16^{\circ}$ \\ ERGODESIGN USIHC CINAHPA}

associadas a deficiências na qualidade do projeto de produto (ASME, 1985; WALLACE; HALES, 1987). Na Alemanha, no entanto, desde 1970 essa área do conhecimento foi investigada, como mostram os estudos de Koller (1976), Pahl e Beitz (1977), Rodenacker (1976) e Roth (1982). Após o estudo de ASME (1985), financiado pela National Science Foundation dos EUA, houve um grande impulso em pesquisa e publicações de resultados como as obras de Andreasin (1983), Blanchard e Fabrycky (1981), Boothroyd (1980), Clausing (1994), Nevis e Whitney (1989), Pugh (1991) e Ullman (1992).

No Brasil, o departamento de Engenharia Mecânica da UFSC foi o primeiro a introduzir disciplinas de metodologia de projeto de produtos na graduação e pós-graduação, em 1976 (BACK et al., 2008), e em 1983 Back publicou a primeira obra em português sobre metodologia de projeto de produtos industriais (BACK, 1983). A partir dessa data vários centros brasileiros introduziram esta área de conhecimento em cursos de graduação e pós-graduação, geralmente nos cursos de engenharia mecânica, engenharia de produção e desenho industrial, e outras obras surgiram, como Rozenfeld et al. (2006), Fuso e Sacomano (2007), Back et al. (2008), Romeiro Filho et al. (2011), Vieira et al. (2013) e Rodrigues et al. (2015).

Segundo Rozenfeld et al. (2006), os modelos de referência para o desenvolvimento de produtos, além de descreverem o processo de desenvolvimento de produtos, surgiram para minimizar erros nesse processo. Por meio deles, pode-se obter uma visão única do processo de desenvolvimento de produtos, nivelando-se os conhecimentos entre os atores que participam de um desenvolvimento específico, e assim a empresa e seus profissionais podem desenvolver produtos segundo um ponto de vista comum.

A partir desse contexto, decidiu-se analisar algumas metodologias e modelos de referência para o desenvolvimento de produtos comumente utilizadas na engenharia, para verificar se a ergonomia é abordada e como é abordada pelos autores. $16^{\circ}$ Ergodesign - Congresso Internacional de Ergonomia e Usabilidade de Interfaces Humano Tecnológica: Produto, Informações Ambientes Construídos e Transporte

$16^{\circ}$ USIHC - Congresso Internacional de Ergonomia e Usabilidade de Interfaces Humano Computador

CINAHPA | 2017 - Congresso Internacional de Ambientes Hipermídia para Aprendizagem.

\section{Procedimentos metodológicos}

A seleção das metodologias de projeto de produtos para análise foi feita a partir dos resultados do diagnóstico desenvolvido com alunos de engenharia da Universidade Federal de Santa Catarina, que permitiu verificar todas as metodologias conhecidas pelos alunos da graduação. Foi aplicado um questionário em todos os alunos matriculados na disciplina de metodologia de projeto de produtos nos cursos de engenharia da Universidade Federal de Santa Catarina, em 2015, sendo esses: Engenharia de Produção, Engenharia Mecânica e Engenharia de Materiais. A amostra do estudo foi composta de 148 alunos distribuídos em três cursos distintos: engenharia mecânica $(n=50)$, engenharia de produção $(n=54)$ e engenharia de materiais $(n=44)$. O tamanho da amostra estratificada foi representativa do total $(\mathrm{N}=161)$, um erro amostral de $4 \%$ e nível de confiança de $95 \%$ foi estabelecido para cada estrato: engenharia mecânica $(\mathrm{N}=55)$, engenharia industrial $(\mathrm{N}=59)$ e engenharia de materiais $(\mathrm{N}=47)$. Esse estudo foi aprovado pelo Comitê de Ética em Pesquisa da Universidade Federal de Santa Catarina, Florianópolis, Santa Catarina, Brasil (CAAE: 48799215.9.0000.0121).

Foi perguntado no questionário, aplicado ao final do período letivo, quais metodologias de projeto de produtos os alunos conheciam, constando todas as opções que aparecem nas ementas das disciplinas e a opção aberta "outras" para preenchimento do aluno. Sendo assim, foram estudadas as obras dos autores citados pelos alunos, analisando as etapas das metodologias de desenvolvimento de produtos, e buscando os termos: "ergonomia", "fatores humanos" e "usuário" nas obras, a fim de verificar a forma como a ergonomia é abordada nessas metodologias e se este poderia ser um fator para o pouco uso da ergonomia pelos engenheiros.

\section{Metodologias de projeto de produto de engenharia}

A seleção das metodologias apresentadas a seguir se deu com base no diagnóstico desenvolvido com
Realização:

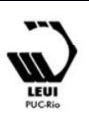




\section{$16^{\circ}$ \\ ERGODESIGN USIHC CINAHPA}

alunos de engenharia de produção, engenharia mecânica e engenharia de materiais da Universidade Federal de Santa Catarina. Foram analisadas todas as metodologias citadas pelos alunos da graduação.

\subsection{Pahl e Beitz (1996)}

No início de 1970, na Alemanha, houve um grande esforço de pesquisa sobre princípios e metodologias de projeto do produto. Essas pesquisas resultaram em diversos trabalhos, e o mais prestigiado é o de Pahl e Beitz (1996), impresso pela primeira vez em 1977. Os autores estabelecem o processo em quatro fases principais: definição da tarefa, projeto conceitual, projeto preliminar e projeto detalhado. A definição da tarefa envolve o planejamento inicial do produto por meio da coleta de informações sobre o mercado, culminando na lista de especificações; o projeto conceitual define o conceito do projeto, através da busca por princípios de trabalho, criação de estruturas funcionais, seleção de uma estrutura adequada consolidando em um princípio de solução; o projeto preliminar tem como saída uma descrição técnica, gerada a partir da definição do leiaute do produto/sistema técnico proposto; e no projeto detalhado o resultado é uma especificação de produção, com os documentos operacionais e de preparação da produção, desenho dos detalhes e listas de peças, custos estimados e instruções de produção, montagem, transporte e funcionamento.

No capítulo de projeto detalhado, os autores alegam que ao projetar para a ergonomia, os projetistas devem prestar atenção em posturas corporais, dimensões e cargas, mas sem apresentar tabelas de valores ou normas ao leitor. É afirmado também que quando o envolvimento de seres humanos é deliberado, este envolvimento deve ser planejado com cuidado e feitos ajustes adequados, começando cedo no processo de projeto, desde a definição da tarefa. Alguns aspectos ergonômicos para a lista de requisitos e critérios de avaliação são apresentados: ser eficaz, simples, rápido, preciso, sem erros, poder ser aprendido, estresse tolerável, baixa fadiga, baixa irritação, nenhum perigo físico, seguro, sem risco para a saúde, sem monotonia, desenvolvimento pessoal. No entanto, $16^{\circ}$ Ergodesign - Congresso Internacional de Ergonomia e Usabilidade de Interfaces Humano Tecnológica: Produto, Informações Ambientes Construídos e Transporte

$16^{\circ}$ USIHC - Congresso Internacional de Ergonomia e Usabilidade de Interfaces Humano Computador

CINAHPA | 2017 - Congresso Internacional de Ambientes Hipermídia para Aprendizagem.

os autores não especificam como aplicar e não explicam esses requisitos.

\subsection{Asimow (1962)}

Para Asimow (1962), o projeto de engenharia é uma atividade que tem como objetivo satisfazer as necessidades humanas, particularmente aquelas que podem ser atendidas pelos fatores tecnológicos. A estrutura proposta pelo autor consiste de 7 fases, começando com uma necessidade primitiva. As 3 primeiras fases referem-se as fases de projeto, sendo elas: estudo de viabilidade, projeto preliminar e projeto detalhado. As outras fases não são consideradas como atividades de projeto, referentes ao planejamento para manufatura, distribuição, consumo e retirada do produto.

No estudo de viabilidade o objetivo é alcançar um conjunto de soluções úteis para o problema de projeto. O projeto preliminar estabelece qual das alternativas oferecidas é o melhor conceito de projeto, para ir para um avaliação mais detalhada de parâmetros de projeto, tolerâncias, materiais. A fase de projeto detalhado começa com o conceito evoluído no projeto preliminar, e fornece a descrição de engenharia de um projeto testado e produzível. Os passos seguintes são planejar e projetar a manufatura, distribuição, consumo e retirada do produto.

No estudo de viabilidade, a análise das necessidades é o primeiro passo. No capítulo 8, análise das necessidades e da atividade, o autor afirma que a declaração primitiva das necessidades deve ser revista em uma situação experimental para fazer um melhor ajuste. $\mathrm{O}$ autor não especifica como isso deve ser feito e afirma que nesta fase do trabalho, a colaboração com um designer industrial ou um especialista em fatores humanos pode ser útil. Portanto, para o autor, a questão da ergonomia fica a cargo de um especialista.

\subsection{Blanchard e Fabrychy (1981)}

O processo proposto por Blanchard e Fabrychy (1981) inicia-se com a definição de uma 


\section{$16^{\circ}$ \\ ERGODESIGN USIHC CINAHPA}

necessidade, o "quer ou deseja" para um sistema/produto. Depois disso, a fase de projeto conceitual é formada pelo estudo de viabilidade (análise das necessidades, exigências, conceito) e o planejamento avançado de produtos (planos e especificação). A fase de projeto preliminar estabelece a análise de funções, síntese preliminar e atribuição de critérios de projeto. $\mathrm{O}$ projeto detalhado é o desenvolvimento em grande escala: projeto detalhado do sistema funcional, dos elementos do sistema de logística de apoio, funções de suporte, dados/documentação, desenvolvimento de protótipo, teste de protótipo e avaliação. A produção e/ou construção, é a fase de fabricação. No uso do produto e suporte é feito a análise e avaliação e a modificação para ação corretiva.

Nesta proposta, os fatores humanos aparecem após a apresentação da metodologia, em projeto para o homem, como algo que pode ser incluído no processo se o objetivo for o projeto ergonômico. Os autores apresentam um conjunto de dados antropométricos (sem referência, país ou população), uma tabela resumida de limites de folgas necessários para várias posições do corpo, espaços necessários para a utilização de ferramentas manuais comuns, campo visual vertical e horizontal, limites desejáveis para ruído (50 a $80 \mathrm{~dB}$ ), temperatura (50 a $55 \mathrm{~F})$, umidade e vibração. Depois disso, é apresentada a ergonomia no ciclo de vida, sem especificar ferramentas ou explicar sua aplicação.

\subsection{Back (1983)}

Back (1983) foi a primeira obra brasileira a tratar do projeto de produtos. $\mathrm{O}$ autor definiu a morfologia do projeto como: estudo de viabilidade, projeto preliminar, projeto detalhado, revisão e testes, planejamento da produção, planejamento do mercado, planejamento para consumo e manutenção e planejamento da obsolescência. $\mathrm{O}$ estudo de viabilidade tem como objetivo o estudo de viabilidade física, econômica e financeira do projeto. O projeto preliminar objetiva fornecer as informações essenciais do projeto, a partir de estudos de síntese, de tolerâncias e materiais, de condições socio-econômicas etc. O projeto $16^{\circ}$ Ergodesign - Congresso Internacional de Ergonomia e Usabilidade de Interfaces Humano Tecnológica: Produto, Informações Ambientes Construídos e Transporte

$16^{\circ}$ USIHC - Congresso Internacional de Ergonomia e Usabilidade de Interfaces Humano Computador

CINAHPA | 2017 - Congresso Internacional de Ambientes Hipermídia para Aprendizagem. detalhado fornece as descrições de engenharia do projeto, chegando-se a um projeto fabricável. A fase de revisão e testes tem o intuito de construir modelos experimentais para verificar formulações ainda não testadas. As fases de planejamento da produção e do mercado planejam detalhadamente os processos de fabricação e um sistema eficiente de distribuição, respectivamente. O planejamento para consumo e manutenção objetiva incorporar aspectos adequados de serviços ao projeto e prover uma base racional para o aperfeiçoamento e reprojeto do produto. O planejamento da obsolescência leva em consideração os problemas associados com a retirada e eliminação do produto.

Na metodologia de Back (1983) existe um capítulo sobre ergonomia/fatores humanos no projeto, que afirma que deve-se estudar os requisitos de quem usa o produto, para descobrir a melhor forma de interpretar estes requisitos em características de projeto e incorporá-los ao produto. Nota-se então que, de acordo com o autor, a ergonomia deve ser considerada na fase de viabilidade, onde são definidos os requisitos.

Apresenta alguns valores da norma ISO 2631 (1974 apud BACK, 1983) de temperatura ideal, níveis de ruídos, aceleração e vibração, dimensões médias do homem e da mulher, espaços adequados para pessoas em pé e sentadas junto de mesas, alturas de bancadas, dimensões de escadas, campo de trabalho no plano horizontal e no plano vertical, e dados diversos de esforços em comandos.

Entretanto são figuras e gráficos com poucas informações e explicações (dado a obsolecência da norma).

\subsection{Pugh (1991)}

O modelo de Pugh consiste de seis passos. Na primeira fase, é feita uma análise de mercado utilizando as informações obtidas a partir dos serviços de atendimento ao cliente, pesquisa de mercado e distribuidores. No próximo passo, as especificações do produto são caracterizadas e, com isso, parte-se para a fase de concepção. Nesta fase, um produto é gerado com base nas especificações. Na fase de projeto detalhado, o produto conceitual recebe detalhamento técnico 


\section{$16^{\circ}$ \\ ERGODESIGN USIHC CINAHPA}

$16^{\circ}$ Ergodesign - Congresso Internacional de Ergonomia e Usabilidade de Interfaces Humano Tecnológica: Produto, Informações Ambientes Construídos e Transporte

$16^{\circ}$ USIHC - Congresso Internacional de Ergonomia e Usabilidade de Interfaces Humano Computador

CINAHPA | 2017 - Congresso Internacional de Ambientes Hipermídia para Aprendizagem. para se tornar um produto real. O próximo passo é a fabricação, que planeja e projeta o processo de fabricação. O passo final é vender. Esta fase irá definir as necessidades do utilizador no contexto, distribuição, serviço de back-up e feedback.

No capítulo 3, especificação do projeto de produto, o autor apresenta como conteúdo de uma especificação de projeto de produto a ergonomia, e descreve-a como uma interface homem-máquina, sendo esta a única informação apresentada sobre ergonomia.

\subsection{Ullman (1992)}

De acordo com Ullman (1992), desde que o projeto é fundamentalmente o esforço para satisfazer uma necessidade, descobrir a necessidade é sempre a primeira fase do processo. Como há sempre mais necessidades do que recursos para atendê-las, a chave é decidir quais ideias de produto desenvolver. Para este autor, o processo de projeto é dividido em descoberta de produtos, que estabelece a necessidade a se trabalhar; o planejamento do projeto, que planeja os recursos da empresa, financeiros, de pessoas e equipamentos; a definição do produto, que identifica os clientes e gera os requisitos e especificações; o projeto conceitual, que gera e avalia conceitos para o produto; o desenvolvimento de produtos, que refina o melhor conceito em um produto real; e o suporte do produto, que administra o apoio de fabricação e montagem.

Neste processo, o autor apresenta, no capítulo 6 sobre a definição do produto, o desenvolvimento de especificações de engenharia, afirmando que "qualquer produto que é visto, tocado, ouvido, sentido, cheirado, ou controlado por um ser humano terá requisitos de fatores humanos " (ULLMAN, 1992, p. 160, tradução nossa). Então, são apresentados alguns dados antropométricos (MILSTD 1472 apud ULLMAN, 1992), de força humana média (adaptado de H. Dreyfuss, The Measure of Man: Human Factors in Design, Whitney Library of Design, New York, 1967) e os usos apropriados de display visual, controles manuais e de pedal (adaptado de G. Salvendy (ed.), Handbook of Human Factors, Wiley, 1987).
Porém, mais uma vez os fatores humanos no projeto não são bem explicados, nem como usar esses dados apresentados.

\subsection{Ulrich e Eppinger (1995)}

A proposta de Ulrich e Eppinger é dividida em 6 fases: planejamento, projeto conceitual, projeto em nível de sistema, projeto detalhado, teste e refinamento, e produção. A primeira fase, planejamento, prevê a declaração da missão do projeto, que especifica o mercado-alvo para o produto, os objetivos do negócio, principais pressupostos e restrições. A fase de conceito gera e avalia conceitos de produtos. No projeto em nível de sistema é definida a arquitetura do produto e a decomposição do produto em componentes e subsistemas. O objetivo do projeto detalhado é completar a especificação da geometria, materiais e tolerâncias de todas as peças únicas no produto e a identificação de todas as peças padrão a serem adquiridas a partir de fornecedores. $\mathrm{Na}$ fase de teste, versões de pré-produção do produto são construídas e avaliadas. A fase de produção produz o produto usando o sistema de produção pretendido, para treinar a força de trabalho e para trabalhar todos os problemas restantes nos processos de produção.

No capítulo 10, design industrial, os autores alegam que as empresas estão cada vez mais usando o design industrial como uma ferramenta importante para atender as necessidades dos clientes e para diferenciar seus produtos dos produtos dos seus concorrentes. Se o produto tem necessidades de ergonomia, é importante ter um designer industrial na equipe de projeto. Para verificar as necessidades de ergonomia, o autor apresenta algumas perguntas: "Qual a importância da facilidade de uso? Quão importante é a manutenção? Quantas interações do usuário são necessárias para as funções do produto? Quais são as questões de segurança?". Portanto, para o autor, a ergonomia fica a cargo de um designer industrial, que participará da equipe se a ergonomia for considerada necessária.

\subsection{Baxter (1998)}

Realização:

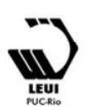




\section{$16^{\circ}$ \\ ERGODESIGN USIHC CINAHPA}

No seu livro, Baxter (1998) apresenta fases gerais para o processo de desenvolvimento de produtos: planejamento do produto, projeto conceitual, projeto detalhado, projeto da configuração e projeto para fabricação. No planejamento de produtos é proposto um novo produto baseado na oportunidade e a especificação do projeto. $\mathrm{O}$ projeto conceitual objetiva produzir princípios de projeto para o novo produto, satisfazendo as exigências do consumidor e diferenciando o novo produto de outros produtos existentes no mercado. Os objetivos do projeto da configuração é projetar os componentes: formas, funções, materiais e processos de fabricação dos componentes, construção de protótipo experimental para testes de desempenho físico. O projeto detalhado é a especificação completa e detalhada do produto: desenhos técnicos e especificações de fabricação. No projeto para fabricação é feito o planejamento da produção, projeto do ferramental e o protótipo de produção.

$\mathrm{Na}$ fase de projeto conceitual, o autor apresenta ferramentas para geração de conceitos como: análise da tarefa, análise das funções do produto, análise do ciclo de vida, análise de valores. $\mathrm{O}$ autor também apresenta a análise ergonômica da tarefa, afirmando que esse aspecto do projeto é uma rica fonte de inspiração para o projeto do produto. A análise da tarefa explora as interações entre $\mathrm{o}$ produto e seu usuário, através de observações e análises.

De acordo com Baxter (1998), a análise da tarefa cobre dois importantes aspectos do desenvolvimento de produtos: ergonomia e antropometria. A ergonomia usa os conhecimentos de anatomia, fisiologia e psicologia, aplicando-os ao projeto de objetos. Para a maior parte dos projetos, é suficiente observar cuidadosamente como as pessoas realizam as tarefas principais e daí extrair os elementos para o projeto.

Antropometria é a medida física das pessoas. Quando se projetam objetos para uso das pessoas, torna-se imprescíndivel usar as medidas dessas pessoas para dimensionar os produtos.

O autor não apresenta mais informações, mas dá um direcionamento ao leitor, afirmando que $16^{\circ}$ Ergodesign - Congresso Internacional de Ergonomia e Usabilidade de Interfaces Humano Tecnológica: Produto, Informações Ambientes Construídos e Transporte

$16^{\circ}$ USIHC - Congresso Internacional de Ergonomia e Usabilidade de Interfaces Humano Computador

CINAHPA | 2017 - Congresso Internacional de Ambientes Hipermídia para Aprendizagem.

existem publicações de dados antropométricos de várias partes do corpo e também de diferentes populações e que mais detalhes podem ser encontrados em bibliografia especializada da área.

\subsection{Rozenfeld et al. (2006)}

O modelo desenvolvido por Rozenfeld et al. (2006) é voltado principalmente para empresas de manufatura de bens de consumo duráveis e de capital. É divido em 3 macrofases de prédesenvolvimento, desenvolvimento e pósdesenvolvimento. A macrofase de PréDesenvolvimento é composta pelas fases de Planejamento Estratégico do Produto e Planejamento do Projeto. Essas fases consideram as estratégias de mercado da empresa permitindo que se crie um portfólio de produtos com o objetivo de atender ao máximo as necessidades e/ou os desejos dos clientes. Também são especificados o escopo do produto e do projeto, bem como são estimados os recursos necessários, o tempo e o custo para o desenvolvimento.

A macrofase de Desenvolvimento, por sua vez, é composta pelas fases Projeto Informacional, Projeto Conceitual, Projeto Detalhado, Preparação para a Produção e Lançamento. Nessa macrofase são definidas as especificações-meta do futuro produto, estudadas alternativas de conceitos para o produto, de maneira a se atingir as especificações anteriormente definidas. Posteriormente, a alternativa escolhida é detalhada nos documentos pertinentes, de maneira a permitir à fabricação do produto, podendo ser iniciada a produção do produto em série. E, por fim, a macrofase PósDesenvolvimento, onde é realizado o acompanhamento do produto em todo o seu ciclo de vida, de maneira a aprimorá-lo ou reparar defeitos que não foram identificados nos protótipos e lote piloto, e é planejada a retirada do produto do mercado.

Na descrição da fase de projeto conceitual, no capítulo 7, os autores afirmam que é necessário definir a ergonomia e estética do produto, já que a interação entre pessoas e produtos desempenha um papel importante na atividade de projeto de produtos. Segundo os autores, para obter um 


\section{$16^{\circ}$ \\ ERGODESIGN USIHC CINAHPA}

produto adequado em termos de ergonomia, devese considerar as seguintes recomendações (MAGRAB, 1997 apud ROZENFELD et al., 2006): Adequar os produtos as caracteristicas fisicas e ao conhecimento do usuário; Simplificar e reduzir as tarefas necessárias para a operação do produto; Prever os possíveis erros humanos; Considerar a idade, gênero, alcance, destreza, força e visão dos usuários.

\subsection{Back et al. (2008)}

O Processo de Desenvolvimento de Produtos proposto por Back et al. (2008), foi desenvolvido com base em pesquisas realizadas no departamento de engenharia mecânica da UFSC. O modelo é formado por três macrofases: Planejamento, Processo de Projeto, e Implementação. Na macrofase de Planejamento, ocorre o planejamento do produto e planejamento do projeto, que resulta no plano de produtos e na definição do escopo, do tempo, custos, qualidade, e outros atributos do projeto.

A próxima macrofase é o processo de projeto, que inclui quatro fases: Projeto informacional, fase em que são definidas as especificações de projeto; Projeto conceitual, onde são geradas as concepções para solucionar o problema, levando em consideração as especificações de projeto; Projeto preliminar, onde é feito o refinamento de dimensões, formas e materiais da concepção; e Projeto detalhado, que especifica detalhadamente as dimensões, tolerâncias, formas geométricas e materiais de todas as partes do produto, obtendo-se listas e desenhos completos para poder planejar o processo de fabricação.

Após esse processo, segue-se a etapa final, Implementação, composta pela preparação da produção, que envolve os passos para fabricar o produto; o lançamento do produto, onde é realizado um trabalho de promoção, para que o produto possa ser comercializado e utilizado pelo consumidor; e a validação do produto, que leva então ao encerramento do projeto.

No capítulo 13, otimização integrada do produto, os autores apresentam a possibilidade de otimizar o $16^{\circ}$ Ergodesign - Congresso Internacional de Ergonomia e Usabilidade de Interfaces Humano Tecnológica: Produto, Informações Ambientes Construídos e Transporte

$16^{\circ}$ USIHC - Congresso Internacional de Ergonomia e Usabilidade de Interfaces Humano Computador

CINAHPA | 2017 - Congresso Internacional de Ambientes Hipermídia para Aprendizagem. projeto na fase de projeto preliminar, considerando atributos específicos que se queira otimizar, por exemplo o atributo ergonomia.

Nesta obra, a ergonomia é apresentada como Projeto para uso amigável, que compreende a fácil operação, a obtenção de resultados confiáveis no uso inicial e repetitivo e a satisfação com o desempenho do produto. Um produto amigável deve melhorar ou ampliar as capacidades humanas, maximizar a utilidade do produto, melhorar a eficiência, a segurança e o conforto. Segundo os autores, uma metodologia para o projeto para uso amigável deve englobar uma análise do usuário, análise da tarefa a executar e a biomecânica envolvida. Entretanto não é apresentado como fazer essas análises e onde encontrar material sobre esse assunto.

\section{Conclusão}

As metodologias analisadas apresentam a ergonomia de forma superficial, como uma responsabilidade de ergonomistas, ou como uma otimização do produto na fase de projeto preliminar. No entanto estas mesmas metodologias afirmam que os custos ficam comprometidos nas fases iniciais do projeto, e que mudanças tardias geram muito custo e desperdício de tempo.

Nota-se que, apesar da importância da ergonomia no projeto de produtos, não há fatores humanos de qualidade suficiente no processo de desenvolvimento de produtos, porque falta conhecimento sobre a utilização da ergonomia ou a sua aplicação é demasiado limitada, resultando em soluções sub-ótimas (DUL et al., 2012). Ao mesmo tempo em que os autores recomendam a utilização da ergonomia, esta é apresentada de forma limitada, não permitindo o adequado entendimento da ergonomia e de suas ferramentas no projeto de produtos. Mesmo que os engenheiros entendam que o produto é desenvolvido para as pessoas, as informações disponíveis para eles são insuficientes para compreender o usuário corretamente. 


\section{$16^{\circ}$ \\ ERGODESIGN USIHC CINAHPA}

$16^{\circ}$ Ergodesign - Congresso Internacional de Ergonomia e Usabilidade de Interfaces Humano Tecnológica: Produto, Informações Ambientes Construídos e Transporte

$16^{\circ}$ USIHC - Congresso Internacional de Ergonomia e Usabilidade de Interfaces Humano Computador

CINAHPA | 2017 - Congresso Internacional de Ambientes Hipermídia para Aprendizagem.

\section{BIBLIOGRAFIA}

ABRAHÃO, J et al. Introdução a ergonomia: da prática a teoria. São Paulo: Blücher, 2010.

ANDREASIN, M. Design for assembly. United Kingdom: Springer Verlag, 1983.

ASIMOW, M. Introduction to design: fundamentals of engineering design. New Jersey: Prentice Hall, 1962.

ASME - National Science Foundation. Goals and priorities for research on design theory and methodology. Technical report, 1985 .

BACK, N. Metodologia de Projeto de Produtos Industriais. Rio de Janeiro: Guanabara, 1983.

BACK, N. et al. Projeto integrado de produtos. Barueri - São Paulo: Manole, 2008.

BAXTER, M. Projeto de Produto: guia prático para o desenvolvimento de produtos. São Paulo: Blücher, 1998.

BLANCHARD, B.; FABRYCKY, W. Systems engineering and analysis. New Jersey: Prenticehall, 1981.

BOOTHROYD, G. Design for assembly: a designer's handbook. Massachusetts, University of Massachusetts, 1980.

BROBERG, O. Integrating ergonomics into the product development process. International Journal of Industrial Ergonomics, v. 19, n. 4, p. 317-327, 1997.

CAIN, W. D. Engineering product design. London: Business Books Ltd., 1969.

CIACCIA, F. R. D. A. S. Entre a vivência do conforto e do desconforto em caines de aeronaves: uma abordagem baseada na atividade. Tese (Doutorado)- Escola Politécnica da Universidade de São Paulo. Departamento de Engenharia de Produção. São Paulo, 2013.
CLAUSING, D. Total quality development $-\mathbf{a}$ step-by-step guide to world-class concurrent engineering. New York: ASME Press, 1994.

DANIELLOU, F. Métodos em ergonomia de concepção. In: DUARTE, F. Ergonomia e Projeto na indústria de processo contínuo. Rio de Janeiro: Editora Lucerna, 2002, p. 29-33.

DEJEAN, P; NÄEL, M. Ergonomia do produto. In: FALZON, P. Ergonomia. São Paulo: Editora Edgar Blucher, 2007, p. 393-405.

DUARTE, F. Ergonomia e Projeto na indústria de processo contínuo. Rio de Janeiro: COPPE/RJ: Lucerna, 2002.

FALZON, Pierre. Ergonomia. São Paulo: Blücher, 2007.

FLORES, C et al. Diseño y usuário: aplicaciones de la ergonomia. México: Editora Desígnio, 2007

FUSCO, J. P. A.; SACOMANO, J. B. Operações e Gestão Estratégica da Produção. São Paulo: Arte e Ciência Editora, 2007.

GOMES FILHO, J. Ergonomia do objeto: sistema técnico de literatura ergonômica. São Paulo: Escrituras Editora, 2003.

IEA (International Ergonomics Association).

Definition of Ergonomics. Council of IEA, 2000. Disponivel em:

$<$ http://www.iea.cc/01 what/What $\% 20$ is $\% 20$ Ergon omics.html>. Acesso em 20 abr. 2015.

IIDA, I. Ergonomia: projeto e produção. 2 ed. São Paulo: Edgar Blutcher, 2005.

ISMAILA, S.O.; SAMUEL, T.M. Human-centered engineering: the challenges of Nigerian engineer. Journal of Engineering, Design and Technology, v. 12 Iss 2 p. 195-208, 2014.

JACKSON, M. A participação de ergonomistas nos projetos organizacionais. Produção, $\mathrm{n}$ especial, p.61-70. 2000 .

JACKSON, M.; DISCHINGER, M.; DUARTE, F.
Realização:

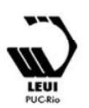




\section{$16^{\circ}$ \\ ERGODESIGN USIHC CINAHPA}

$16^{\circ}$ Ergodesign - Congresso Internacional de Ergonomia e Usabilidade de Interfaces Humano Tecnológica: Produto, Informações Ambientes Construídos e Transporte

$16^{\circ}$ USIHC - Congresso Internacional de Ergonomia e Usabilidade de Interfaces Humano Computador

CINAHPA | 2017 - Congresso Internacional de Ambientes Hipermídia para Aprendizagem.
The use of narratives for generating knowledge about the ergonomists role in design processes. In: Annual Congress of the Nordic Ergonomics Society. 39, 2007, Lysekil -Suécia. Anais... Lysekil, 2007.

KOLLER, R. Konstruktionslehre Fur Den Maschinem, Gerate Und Apparatebav. Berlim: Springer Verlag, 1976.

KRICK, E. V. An introduction to engineering and engineering design. New York: John Wiley \& Sons, 1965.

MORAES, A. M.; MONT'ALVÃO, C. Ergonomia: conceitos e aplicações. Rio de Janeiro: 2ab, 1998.

\section{NEVIS, J. L.; WHITNEY, D. L. Concurrent design of products and processes. New York: McGraw-Hill,1989.}

PAGE, A et al. Nuevas técnicas para el desarrollo de productos innovadores orientadores al usuario. Valencia: IBV, 2001.

PAHL, G.; BEITZ, W. Engineering Design: a systematic approach. London: Springer, 1996.

PUGH, S. Total Design. Wokinghem: Addison Wesley, 1991.

SILVA, C. E. S.; NETO, M. F.; FILHO, J. L. F. S. A integração da ergonomia no desenvolvimento de produtos. In: ENEGEP, 8, 1998, Niterói. Anais... Niterói, 1998.

RODENACKER, W. G. Methodisches

Konstruieren. Berlim: Springer Verlag, 1976.

RODRIGUES, A. R.; SOUZA, A. F. de; BRAGHINI JUNIOR, A.; BRANDÃO, C. C.; SILVEIRA, C. C. Desenho Técnico Mecânico: Projeto e Fabricação no Desenvolvimento de Produtos Industriais. Rio de Janeiro: Elsevier Editora LTDA, 2015.

ROMEIRO FILHO, E.; FERREIRA, C. V.; CAUCHICK MIGUEL, P.A.; GOUVINHAS, R. P.; NAVEIRO, R. M. Projeto do Produto. Rio de
Janeiro: Elsevier Editora LTDA, 2011.

ROOZENBURG, N.F.M., EEKELS, J. Product Design, Fundamentals and Methods, Wiley: Chichester, UK, 1995.

ROTH, K. Konstruieren mit konstruktions katalogen. Berlim: Springer Verlag, 1982.

ROZENFELD, H. et al. Gestão de Desenvolvimento de Produtos: Uma referência para a melhoria do processo. São Paulo: Saraiva, 2006.

ULLMAN, D. G. The mechanical design process. New York: McGraw-Hill, 1992.

ULRICH, K.T; EPPINGER, S. D. Product design and development. New York: McGraw-Hill, 1995.

VERGARA, L. G. L. Avaliação do ensino de ergonomia para o design aplicando a teoria da resposta ao item (TRI). Tese (Doutorado) Universidade Federal de Santa Catarina. Programa de Pós-Graduação em Engenharia de Produção. Florianópolis, 2005.

VIDOSIC, J. P. Elements of design engineering. New York: John Wiley \& Sons, 1969

VIEIRA, D.; BOURAS, A.; DEBAECKER, D. Gestão do Projeto do Produto. Rio de Janeiro: Elsevier Editora LTDA, 2013.

WALLACE, K. M.; HALLES, C. Some applications of a systematic design approach in Britain. Konstruktion, n 7, p. 275-279, 1987.

WISNER, A. Por dentro do trabalho. São Paulo: Oboré, 1987.

WOODSON, T. T. Introduction to engineering design. New York: McGraw-Hill, 1966. 